\title{
Traduire
}

Une autre perspective sur r tr traduction

Revue française de la traduction

$225 \mid 2011$

Traduire hors des sentiers battus

\section{Complètement siglé}

\section{Claudie Pons}

\section{(2) OpenEdition \\ Journals}

Édition électronique

URL : http://journals.openedition.org/traduire/117

DOI : 10.4000/traduire. 117

ISSN : 2272-9992

Éditeur

Société française des traducteurs

Édition imprimée

Date de publication : 15 décembre 2011

Pagination : 138

ISBN : 039-773X

ISSN : 0395-773X

Référence électronique

Claudie Pons, «Complètement siglé », Traduire [En ligne], 225 | 2011, mis en ligne le 10 février 2014, consulté le 15 septembre 2020. URL : http://journals.openedition.org/traduire/117 


\title{
Complètement siglé
}

\author{
Claudie Pons
}

\section{NOTE DE L'ÉDITEUR}

Ce billet a été publié dans le Courrier des lecteurs du numéro 3220 de Télérama 1-7 octobre 2011.

$1 \quad$ TRA = Télérama 2319 du 24 au 30 septembre 2011, au hasard des articles : YC = Yves Calvi ? (ou: You Cknow, in French in ze text?), DSK= Dominique Strauss-Kahn? (ou : Donnez sans kompter ?), NKM = Nathalie Kosciusko-Morizet? (pourquoi la réduire ainsi ?), MMA (à ne pas confondre avec MAM) = Quelle assurance avons-nous ?, GR = Guillaume Roquette? (ou : chemin de Grande Randonnée ?), DdV (à ne pas confondre avec DVD) = Dominique de Villepin? Fabuleux, en plus de ne devenir que des numéros, des codes, auprès de l'URSSAF, de la RSI, de la SS, de la CIPAV, de la CE, de la BNP, du CA, du SIE, du SIP, de la CAF, de l'ARA- PL, de la DDE, et j'en oublie beaucoup, il faut que nous parvenions, nous Pauvres Citoyens (PC, à ne pas confondre avec Personal Computer même si on en a un), à faire désormais un décryptage fastidieux dans un magazine que l'on lit pour sa qualité en général. L'idée des sigles et acronymes n'est pas nouvelle, certes, mais peut devenir pénible, à tout bout de champ. Est-ce un pHM ( = phénomène de mode ?).

CP (Hé, hé, à vous de trouver), Vaugines 